\title{
Distribuição de Aedes aegypti e do dengue no Estado do Maranhão, Brasil
}

\author{
Distribution of Aedes aegypti and dengue \\ in the State of Maranhão, Brazil
}

José Manuel Macário Rebêlo 1 Jackson Maurício Lopes Costa 1 Francinaldo Soares Silva 1 Yrla Nívea Oliveira Pereira 1 Jocel ma Matos da Silva 1

\footnotetext{
1 Núcleo de Patologia Tropical e Medicina Social, Departamento de Patologia, Universidade Federal do Maranhão. Praça Madre Deus 2 São Luís, MA 65025-560, Brasil.
}

A bstract Dengue and Aedes aegypti are widespread in the State of Maranhão. During 1995, 87 of the 136 of the State's counties, including 176 towns and 480,687 households, were studied, of which 30 counties (34.4\%), 118 towns (67.0\%) and 10,357 households (2.1\%) were positive for Aedes aegypti. The positi ve counti es are distributed as follow: 3 on São Luís Island, 7 in the Amazonia of Maranhão, 12 in the southern zone of the cerrados or savannas, and 5 in the mixed forest/savanna/palm grove zone. One positive county for Ae. aegypti was located in each of the following: alluvial fields, forest/palm grove, and sand dune/shoals areas. The Ae. aegypti-positive household rates were higher in the Amazonia of Maranhão (3.5\%) and on São Luís Island (2.5\%), because they are the most heavily traveled migratory and trade routes between Maranhão and nei ghboring states and are also the State's main economic centers. Househol d infestation rates for Ae. aegypti and reported dengue case rates were higher during the rainy season, showing the importance of rain in forming prime breeding sites for Aedes and spreading dengue.

Key words Aedes; Dengue; DiseaseVectors

Resumo O dengue o Aedes aegypti encontram-se disseminados em municípios de todas as regi ões do Maranhão. No ano de 1995, foram trabal hados 87 dos 136 municípi os em que se divide geografi camente o Estado, 176 l ocali dades e 480.687 imóveis. Foram considerados positivos para Ae. aegypti trinta municípios (34,4\%), 118 localidades (67,0\%) e 10.357 imóveis (2,1\%). Dos municípios positivos, três pertencem à Il ha de São Luís, sete à Amazônia Maranhense, 12 à zona dos cerrados meridionais, cinco à zona mista de matas-cerrados-cocais. Nas zonas que seguem campos aluviais, matas-cocai s e dunas-restinga - , Ae. aegypti foi encontrado em apenas um município. Osíndices de positividade predial foram mais elevados na Amazônia Maranhense (3,5\%) ena Il ha deSão Luís (2,5\%), por constituírem as rotas de mai or fluxo migratório da população e de escoamento de produtos entre o Maranhão e os estados vi zi nhos e também por serem áreas onde estão l ocal izados os grandes centros urbanos e econômi cos do Estado. Os índices de infestação predial por Ae. aegypti e de casos de dengue notifi cados foram maiores nos meses úmidos, mostrando a importância das chuvas na formação de criadouros do vetor e na distribuição de Aedes e do dengue.

Palavras-chave Aedes; Dengue; Vetores de Doenças 
Introdução

A distribuição do vetor do dengue, o Aedes aegypti, é cada vez mais abrangente. O rápido crescimento e urbanização das populações nas áreas tropicais, sem infra-estrutura básica de saneamento, ampliou a faixa de ocorrência desta arbovirose, em razão da difusão do mosquito em áreas antes livres da doença. Esse mosquito é também vetor urbano da febre amarela, aumentando o risco de urbanização dessa doença, mantida primariamente em área silvestre por mais de meio século (Mondet et al., 1996). Entretanto, ao contrário da febre amarela, o dengue apresenta um único ciclo epidemiológico, o urbano. Os principais elementos desse ciclo são o homem (o hospedeiro) e o Ae. aegypti (o vetor).

O Ae. aegypti é um vetor oriundo do continente africano (Chiaravalloti-Neto, 1997), trazido juntamente com os escravos (Chieffi, 1985). Foi erradicado do Brasil pela primeira vez em 1958, mas, em 1967, reapareceu em São Luís e Belém, sendo em seguida eliminado (Franco, 1976). Em 1976, com origem em um foco em Salvador, inicia-se a recolonização no Brasil. Em 1977, foi encontrado no Rio de Janeiro e Santos; em 1979, em Natal, e em 1981, no Paraná (Marques, 1985; Neves et al., 1995). Durante esses anos, as medidas de controle eram esporádicas e isoladas. Isso fez com que em 19851986, o Ae. aegypti fosse encontrado em praticamente em todos os estados brasileiros ( $\mathrm{Ne}$ ves et al., 1995).

O controle do dengue vem sendo um dos maiores desafios na saúde pública do País. Desde que foi detectada a presença do Ae. aegypti em São Paulo, em 1985, até meados de 1995, 595 municípios paulistas encontravam-se infestados por esse vetor (Neves \& Pinho, 1996). Na região de São José do Rio Preto, São Paulo, de 1981 a 1991, Ae. aegypti apresentou contínuo processo de colonização, propagando-se além do município-sede da região (Chiaravalloti-Neto, 1997).

No Nordeste, a situação não é diferente. Para se ter uma idéia, no ano de 1995, do total de casos de dengue notificados no Brasil até o mês de setembro, $74,9 \%$ eram oriundos dessa região. O Estado do Maranhão apresentou-se como o de maior incidência, com $38,8 \%$ dos casos nordestinos e $29 \%$ dos casos registrados em todo o Brasil. O segundo estado mais importante foi o Ceará, com $29 \%$ e $21,8 \%$ dos casos, respectivamente. Dos estados nordestinos, apenas Sergipe e Bahia deixaram de notificar. Isso mostra a extensão do domínio do Ae. aegypti no Brasil. Naquele ano, já havia registro de dengue também no Rio de Janeiro, Mato Grosso do Sul e Goiás.

Com este trabalho, pretende-se determinar a distribuição do Ae aegypti nos municípios do Maranhão, tendo como base inquéritos entomológi cos realizados no ano de 1995 nas diversas zonas ecológicas existentes no Estado e os casos de dengue nos anos de 1995-1996.

\section{Metodologia}

As informações apresentadas e discutidas neste trabalho derivam do levantamento de formas adultas e imaturas de Ae. aegypti realizado pela Fundação Nacional de Saúde (FNS), Regional do Maranhão, nos anos de 1995 e 1996. Os dados referentes à distribuição do Ae. aegypti no Maranhão correspondem ao ano de 1995 e estão organizados de acordo com os municípios, localidades e imóveis positivos. Os dados sobre a flutuação mensal dos mosquitos na infestação predial e a variação mensal na freqüência de casos de dengue notificados correspondem ao ano de 1996. Os dados pluviométricos utilizados correspondem também ao ano de 1996 e foram obtidos no Instituto Brasileiro de Geografia e Estatística (IBGE)/ São Luís-MA.

A rotina de captura das formas adultas incluía o exame de todos os cômodos das casas, começando a inspeção à direita da porta que dá acesso ao cômodo imediato, e circulando de modo a manter a parede sempre à direita do capturador. Todas as paredes, móveis, objetos e roupas eram verificadas à luz da lanterna, quando necessário. Para a captura das formas imaturas, todos os depósitos que continham água eram cuidadosamente examinados. A inspeção iniciava pelo peridomicílio (pátio, quintal, jardim), seguindo sempre pela direita. Terminada a visita externa, prosseguia-se a inspeção dentro das casas. Esse método foi adaptado daquele utilizado no Programa de Controle da Febre amarela (MS, 1989).

O estudo foi realizado em 87 dos 136 municípios que compõem o Estado do Maranhão. Para efeito de discussão, agruparam-se os municípios em oito zonas fitogeográficas, ficando os 136 municípios assim distribuídos: cerrados meridionais, (25 municípios); Amazônia (18); cerrado e caatinga (8); dunas, mangue e restinga (13); campo aluvial fluviomarinho (28); matas, cocais e cerrados (18); matas e cocais (23). Os três municípios restantes pertencem à Ilha de São Luís, a qual não se ajusta a nenhuma das zonas mencionadas (Figura 1), por apresentar um misto de matas, cerrados, cocais, dunas, restingas e mangues. 
Figura 1

Mapa do estado do Maranhão mostrando as zonas ecológicas e os municípios onde foram detectados a presença de Aedes aegypti e casos humanos de dengue.

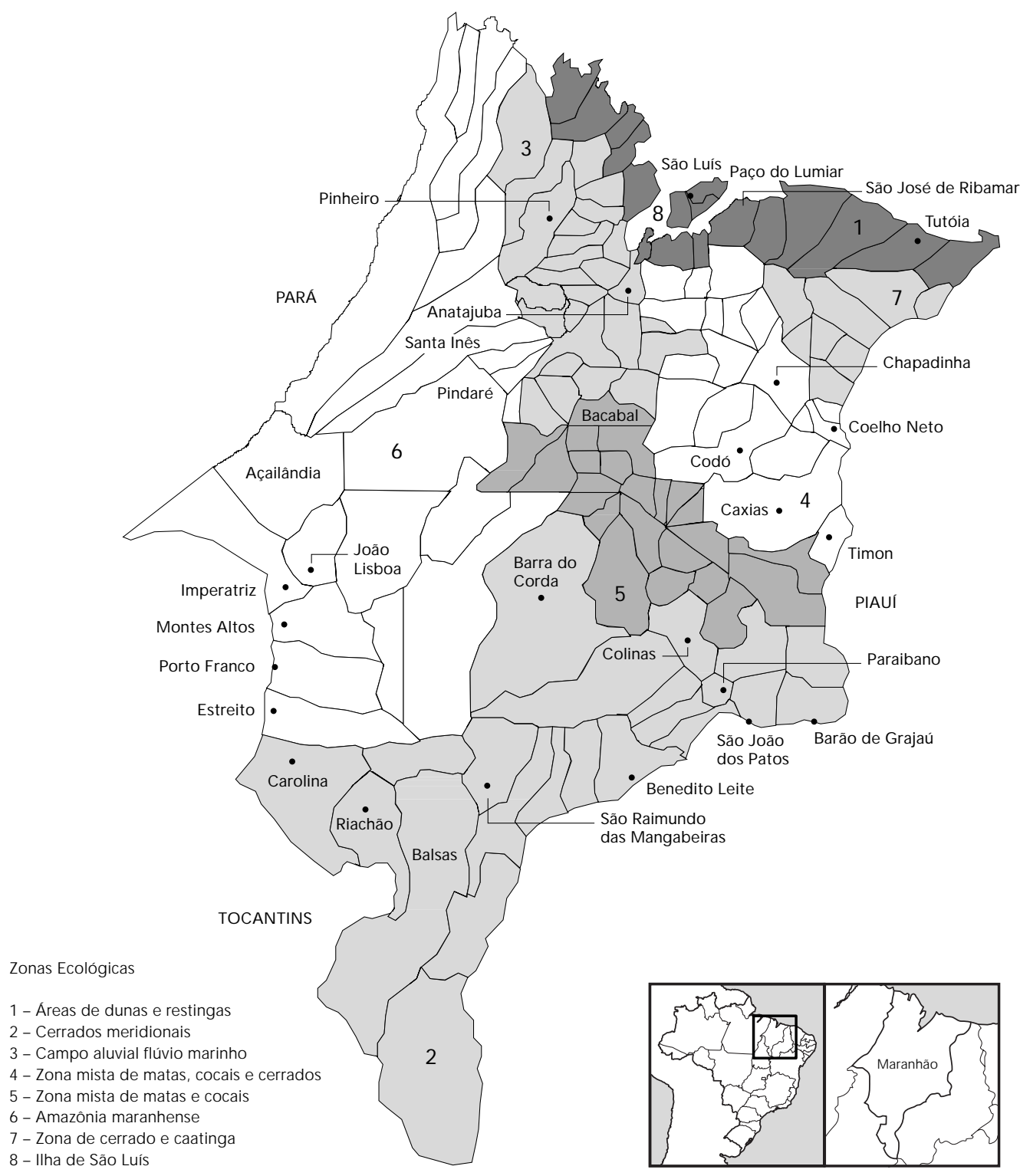




\section{Resultados}

No total, foram trabalhados 87 municípios, 176 localidades e 480.687 imóveis. Foram considerados positivos para Ae. aegypti trinta municípios (34,4\%), 118 localidades (67\%) e 10.357 imóveis (2,1\%). Na Figura 1 e nas Tabelas 1 a 5 , são apresentados somente os municípios com localidades e imóveis positivos.

Na Amazônia Maranhense, foram trabalhados 15 municípios, entretanto somente sete $(46,7 \%)$ resultaram positivos para o Ae. aegypti, conforme a Tabela 1 . O mosquito estava presente em 76,5\% (26) das 34 localidades investi- gadas. O índice de positividade para os imóveis foi na ordem de $3,5 \%$. Os municípios com maiores infestações nos imóveis foram Açailândia (13,3\%) e Amarante (13\%), mas o maior número de espécimens foi encontrado em Imperatriz e Porto Franco.

Em direção ao sul do Maranhão, nos cerrados meridionais, o Ae. aegypti foi detectado em 12 dos 17 municípios trabalhados, estando presente em 12 (70,6\%) das 17 localidades inspecionadas. O índice de positividade dos imóveis foi de $2 \%$ (Tabela 2).

Nas áreas mistas de matas, cerrados e cocais, o Ae. aegypti encontrava-se distribuído

Tabela 1

Levantamento das localidades e imóveis positivos para Aedes (S.) aegypti nos municípios da Amazônia Maranhense, em 1995.

\begin{tabular}{lccrcc}
\hline Municípios & \multicolumn{2}{c}{ Localidades } & \multicolumn{2}{c}{ Imóveis } & (\%) Imóveis \\
& Inspecionadas & Aedes aegypti & Inspecionados & Aedes aegypti & \\
\hline Açailândia & 4 & 2 & 724 & 96 & 13,3 \\
Amarante & 1 & 1 & 5.519 & 718 & 13,0 \\
Porto Franco & 6 & 4 & 20.759 & 1.019 & 4,9 \\
Grajaú & 3 & 2 & 1.196 & 67 & 5,6 \\
Imperatriz & 14 & 14 & 105.629 & 2.576 & 2,4 \\
J oão Lisboa & 3 & 1 & 4.389 & 396 & 9,0 \\
Santa Inês & 3 & 2 & 2.222 & 69 & 3,1 \\
Total & 34 & 26 & 14.0438 & 4.941 & 3,5 \\
\hline
\end{tabular}

Tabela 2

Levantamento das localidades e imóveis positivos para Aedes (S.) aegypti nos municípios dos cerrados meridionais do Maranhão, em 1995.

\begin{tabular}{|c|c|c|c|c|c|}
\hline \multirow[t]{2}{*}{ Municípios } & \multicolumn{2}{|c|}{ Localidades } & \multicolumn{2}{|c|}{ Imóveis } & \multirow[t]{2}{*}{ (\%) Imóveis } \\
\hline & Inspecionadas & Aedes aegypti & Inspecionados & Aedes aegypti & \\
\hline Balsas & 1 & 1 & 35.029 & 1.511 & 4,30 \\
\hline Barão de Grajaú & 1 & 1 & 7.789 & 1 & 0,01 \\
\hline Barra do Corda & 2 & 1 & 16.355 & 148 & 0,90 \\
\hline Benedito Leite & 1 & 1 & 1.683 & 56 & 3.32 \\
\hline Carolina & 1 & 1 & 15.310 & 53 & 0,34 \\
\hline Colinas & 1 & 1 & 4.900 & 1 & 0,02 \\
\hline Montes Altos & 2 & 1 & 2.333 & 70 & 3,00 \\
\hline Paraibano & 1 & 1 & 1.034 & 47 & 4,54 \\
\hline Estreito & 1 & 1 & 20.852 & 472 & 2,30 \\
\hline Riachão & 2 & 1 & 13.663 & 178 & 1,30 \\
\hline São J oão dos Patos & 2 & 1 & 23.609 & 361 & 1,52 \\
\hline $\begin{array}{l}\text { São Raimundo } \\
\text { das Mangabeiras }\end{array}$ & 2 & 1 & 14.352 & 206 & 1,43 \\
\hline Total & 17 & 12 & 156.909 & 3.104 & 2,00 \\
\hline
\end{tabular}


em cinco (45,5\%) dos 11 municípios trabalhados e em 13 (52\%) das 25 localidades estudadas. Nessa região, o índice de positividade dos imóveis foi 2,3\% (Tabela 3). A maioria dos municípios manteve um certo padrão no número de casos, o que demonstra que o Aedes está homogeneamente disseminado nessa região do Estado.

Na zona de campo aluvial fluviomarinho, a única localidade inspecionada do Município de Anajatuba resultou positiva e o índice de positividade dos imóveis foi $1,2 \%$. Na zona das matas e cocais, o Ae. aegypti esteve presente em uma das 11 localidades inspecionadas do Município de Bacabal. O índice de infestação predial foi muito baixo. Na zona das dunas e restinga, foram positivas duas das 12 localidades inspecionadas, todas pertencen- tes ao Município de Tutóia. O índice de infestação predial foi menor que a unidade (Tabela 4).

Já na Il ha de São Luís, também localizada ao norte do Estado, todos os três municípios estavam infestados pelo Ae. aegypti, sendo positivas 63 (84\%) das 75 localidades investigadas e 2,5\% dos imóveis (Tabela 5).

Infelizmente, não se dispõe de dados sobre o número de imóveis infestados, mensalmente, pelo Ae. aegypti, para estabelecer a flutuação da infestação predial durante o ano de 1995. Todavia, os índices mensais de casos de infecção pelo dengue naquele ano estão apresentados na Figura 2. Conforme pode observar-se, os índices de casos notificados foram muito mais elevados nos dois primeiros meses do ano (coincidindo com as primeiras

Tabela 3

Levantamento das localidades e imóveis positivos para Aedes (S.) aegypti nos municípios dos cerrados, matas e cocais do nordeste do Maranhão, em 1995.

\begin{tabular}{lrrrrr}
\hline Municípios & \multicolumn{2}{c}{$\begin{array}{c}\text { Localidades } \\
\text { Inspecionadas }\end{array}$} & $\begin{array}{c}\text { Imóveis } \\
\text { Aedes aegypti }\end{array}$ & Inspecionados & Aedes aegypti \\
\hline Caxias & 12 & 4 & 6.879 & 301 & 4,37 \\
Codó & 1 & 1 & 5.578 & 213 & 3,81 \\
Coelho Neto & 1 & 1 & 1.517 & 1 & 0,06 \\
Timon & 1 & 1 & 5.916 & 290 & 4,90 \\
Chapadinha & 10 & 6 & 27.190 & 258 & 0,94 \\
Total & 25 & 13 & 47.080 & 1.063 & 2,30 \\
\hline
\end{tabular}

Tabela 4

\begin{tabular}{|c|c|c|c|c|c|}
\hline \multirow[t]{2}{*}{ Municípios } & \multicolumn{2}{|c|}{ Localidades } & \multicolumn{2}{|c|}{ Imóveis } & \multirow[t]{2}{*}{ (\%) Imóveis } \\
\hline & Inspecionadas & Aedes aegypti & Inspecionados & Aedes aegypti & \\
\hline \multicolumn{6}{|c|}{$\begin{array}{l}\text { Campo aluvial } \\
\text { fluviomarinho }\end{array}$} \\
\hline Anajatuba & 1 & 1 & 231 & 15 & 1,20 \\
\hline \multicolumn{6}{|c|}{$\begin{array}{l}\text { Zona das matas } \\
\text { e cocais }\end{array}$} \\
\hline Bacabal & 11 & 1 & 12.023 & 10 & 0,08 \\
\hline \multicolumn{6}{|c|}{$\begin{array}{l}\text { Áreas de dunas } \\
\text { e restinga }\end{array}$} \\
\hline Tutóia & 12 & 2 & 9.711 & 24 & 0,25 \\
\hline Total & 24 & 4 & 21.965 & 49 & 0,22 \\
\hline
\end{tabular}


Números de localidades e imóveis positivos para Aedes (S.) aegypti na llha de São Luís - MA, em 1995.

\begin{tabular}{lrcrcc}
\hline Municípios & \multicolumn{2}{c}{ Localidades } & \multicolumn{2}{c}{ Imóveis } & (\%) Imóveis \\
& Inspecionadas & Aedes aegypti & Inspecionados & Aedes aegypti & \\
\hline São Luís & 65 & 55 & 38.820 & 1.141 & 2,93 \\
S. J. de Ribamar & 8 & 4 & 6.045 & 16 & 0,26 \\
Paço do Lumiar* & 2 & 4 & 2.587 & 43 & 1,66 \\
Total & 75 & 63 & 47.452 & 1.200 & 2,52 \\
\hline
\end{tabular}

* Em 1996 o município foi desmembrado, criando-se o Município de Raposa.

Figura 2

Flutuação mensal do número de casos de dengue diagnosticados no período de janeiro a dezembro de 1995 , no Estado do Maranhão.

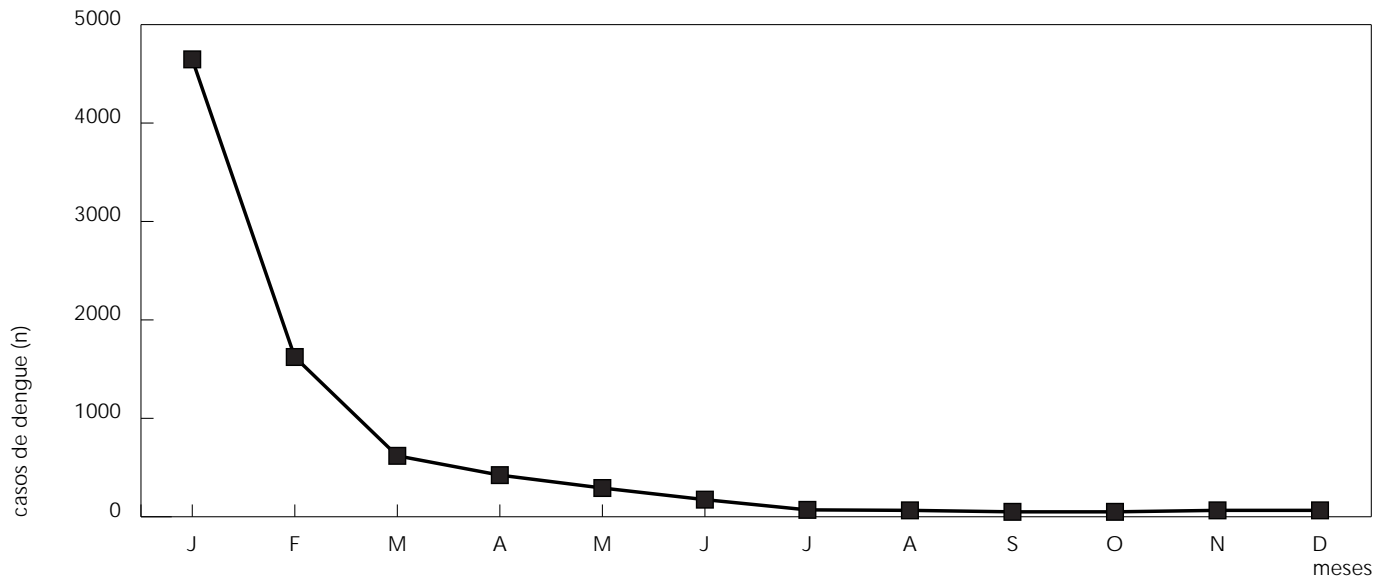

chuvas), caindo sensível e progressivamente a partir de março para números pouco significativos até o mês de dezembro, final da estação seca.

Com relação ao ano de 1996, o inquérito entomológico realizado mostrou que o Ae. aegypti esteve presente nos imóveis o ano inteiro, independente da região do Estado do Maranhão onde foi encontrado. Os índices de infestação predial foram maiores nos meses de janeiro e maio, no período chuvoso, e novembro, no final do período seco (Figura 3). Na Figura 4, selecionaram-se os Municípios de Imperatriz, Caxias, São Luís e Balsas, todos localizados em áreas extremas do Estado, com o propósito de comparar o padrão mensal de incidência do dengue com a variação sazonal dosíndices de infestação predial por Ae. aegypti e da precipitação pluviométrica nessas áreas ecologicamente diferentes. Em todas as áreas, as chuvas foram mais freqüentes no primeiro semestre (estação chuvosa), atingindo o pico em março e/ ou abril. Os meses de junho a setembro foram os mais secos. A incidência dos casos de dengue segue um padrão similar àquele apresentado pelo regime pluvial, concentrando-se no período de maior pluviosidade. O predomínio de Ae. aegypti neste período ficou evidente nos quatro municípios em questão, entretanto, em Caxias e Balsas, houve uma tendência do Ae. aegypti ressurgir nos meses mais secos do segundo semestre, sendo o clima variável entre semi-úmido e semiárido. 
Flutuação mensal do número de casos de dengue e índices percentuais de infestação predial por Aedes aegypti de janeiro a dezembro de 1996, no Estado do Maranhão.

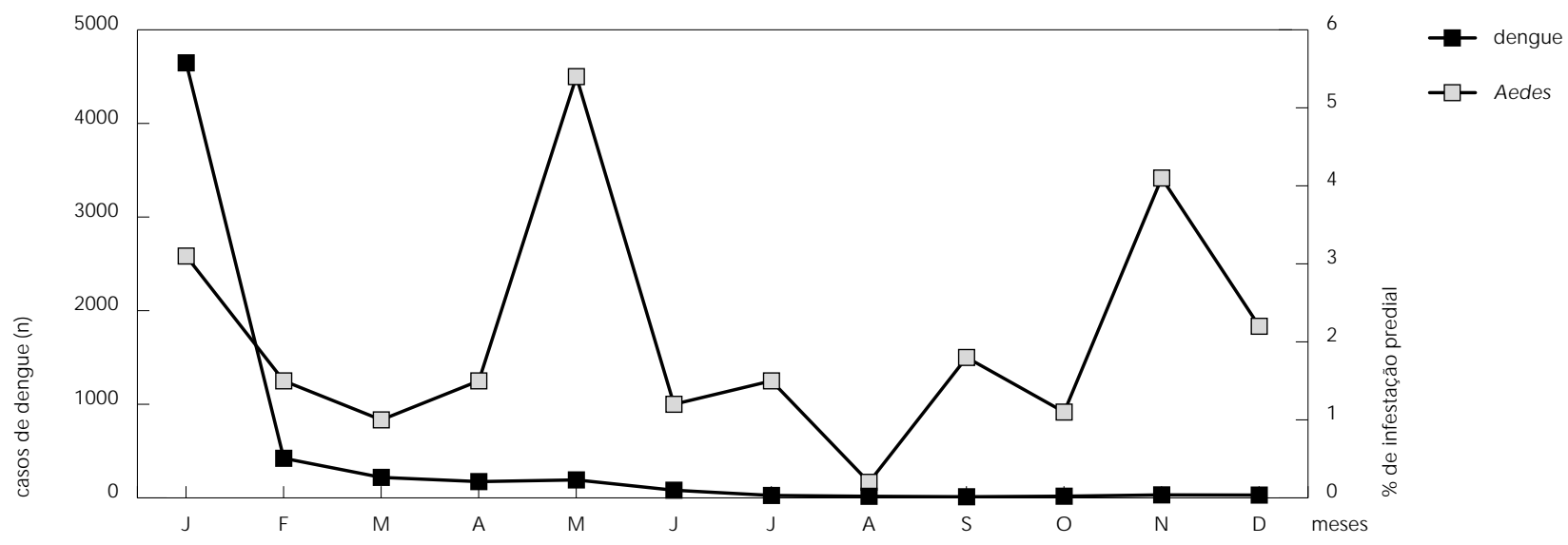

\section{Discussão}

O mosquito Ae. aegypti era, primariamente, uma espécie florestal com larvas bromelícolas, mas se adaptou aos hábitos domiciliares. Esse inseto prefere a umidade, sendo mais comum no litoral e ao longo dos cursos d'água, mas isso não implica a sua inexistência em lugares áridos. É o que se verificou com a distribuição rural em vastas áreas semi-áridas do nordeste brasileiro (Pessôa \& Martins, 1978).

No Maranhão, o Ae. aegypti encontra-se em franca expansão, estando presente nas áreas urbanas da Il ha de São Luís, na zona do litoral e até nos municípios mais meridionais. O Maranhão é um estado complexo do ponto de vista ecológico, por causa da sua posição entre as regiões áridas nordestinas e úmidas amazônicas, tendo o lado limítrofe com o Pará dominado pela Floresta Amazônica, e o lado limítrofe com o Piauí dominado pelos cerrados e manchas de caatingas. Entre estas duas formações, domina um misto de mata e palmeira babaçu, a zona dos cocais. Mais para o sul, o domínio é dos cerrados, que se estendem desde os Estados de Goiás e Tocantins, com características climáticas mais secas. Todas essas áreas, sem distinção, encontram-se colonizadas pelo Ae. aegypti. Para se ter uma idéia, basta verificar que, nas zonas mais áridas do Estado, o Ae. aegypti surge infestando um grande percentual dos municípios. Assim, até 1995-1996, já se encontravam colonizados por este mosquito cer- ca de $52,2 \%$ dos 23 municípios trabalhados, na ocasião, na zona dos cerrados meridionais, e $44,4 \%$ dos nove municípios estudados na zona dos cocais. Esse fato mostra a capacidade de adaptação dessa espécie às diferentes regiões climáticas. Até 1995-1996, as zonas menos afetadas pelo Aedes foram os cerrados do médio e baixo Parnaíba, a baixada oriental e o litoral oriental.

A Ilha de São Luís, entretanto, surge como uma das zonas de maior incidência desse vetor. Todos os municípios que formam a llha encontram-se positivos, com um grande percentual de localidades infestadas. Neste aspecto, a Ilha vem constituindo-se como centro principal de dispersão do mosquito.

A alta densidade de imóveis infestados na Ilha de São Luís deve-se, entre outros, à grande concentração populacional em aglomerados de habitações sem saneamento básico na periferia da capital, o principal centro econômico do Estado. O fluxo migratório da população entre o interior e a capital tem-se intensificado nos últimos anos e propiciado a disseminação do mosquito de São Luís para áreas anteriormente livres do vetor. Deve-se mencionar também que a llha sedia um dos principais portos hidroviários do País, o Itaqui, o qual pode servir de rota para o fluxo do mosquito entre os diversos estados do país e o exterior.

O predomínio do Ae. aegypti nos municípios de áreas úmidas ficou evidente na ampla 
Flutuação mensal do número de casos de dengue, índices percentuais de infestação predial por Aedes aegypti e do regime pluvial de janeiro a dezembro de 1996, no Estado do Maranhão.
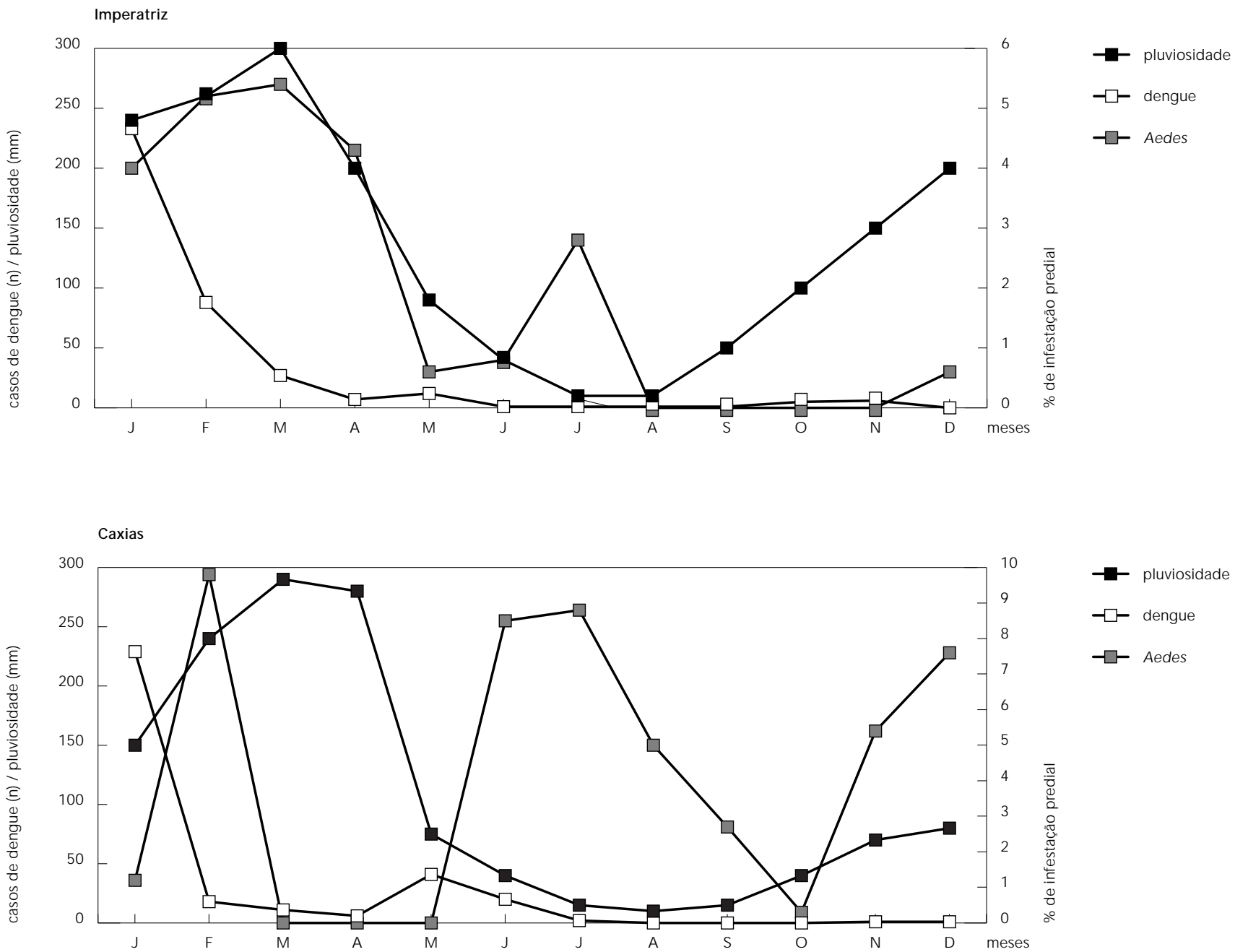

distribuição do mosquito e do dengue, não só na Il ha de São Luís, como também na Amazônia Maranhense. Esta última região adquire grande importância na disseminação de ambos, pois serve de corredor para importantes vias rodoviárias (São Luís-Belém e Belém-Brasília) e ferroviárias (Carajás e Norte-Sul), as quais são utilizadas tanto no fluxo migratório, quanto para o escoamento de produtos entre os Estados do Pará, Maranhão e aqueles do Centro-Sul do Brasil. É possível que o mosquito do dengue tenha-se dispersado até os municípios meridionais do Estado por essas rotas.
Quando se analisa o padrão de ocorrência mensal do Ae. aegypti, logo se observa uma nítida mudança na sua densidade durante o ano, variando de acordo com a flutuação no regime pluvial. Independente da região ecológica, há uma tendência geral de os mosquitos concentrarem suas atividades como adultos na estação chuvosa. Este padrão reflete-se também na distribuição do dengue ao longo do ano. Em 1995, o número de casos de dengue em todo o Estado foi significativamente maior na estação chuvosa, especialmente nos primeiros meses (janeiro-março). No final desta estação e durante todo o período seco, houve uma sensível 
Flutuação mensal do número de casos de dengue, índices percentuais de infestação predial por Aedes aegypti e do regime pluvial de janeiro a dezembro de 1996, no Estado do Maranhão.
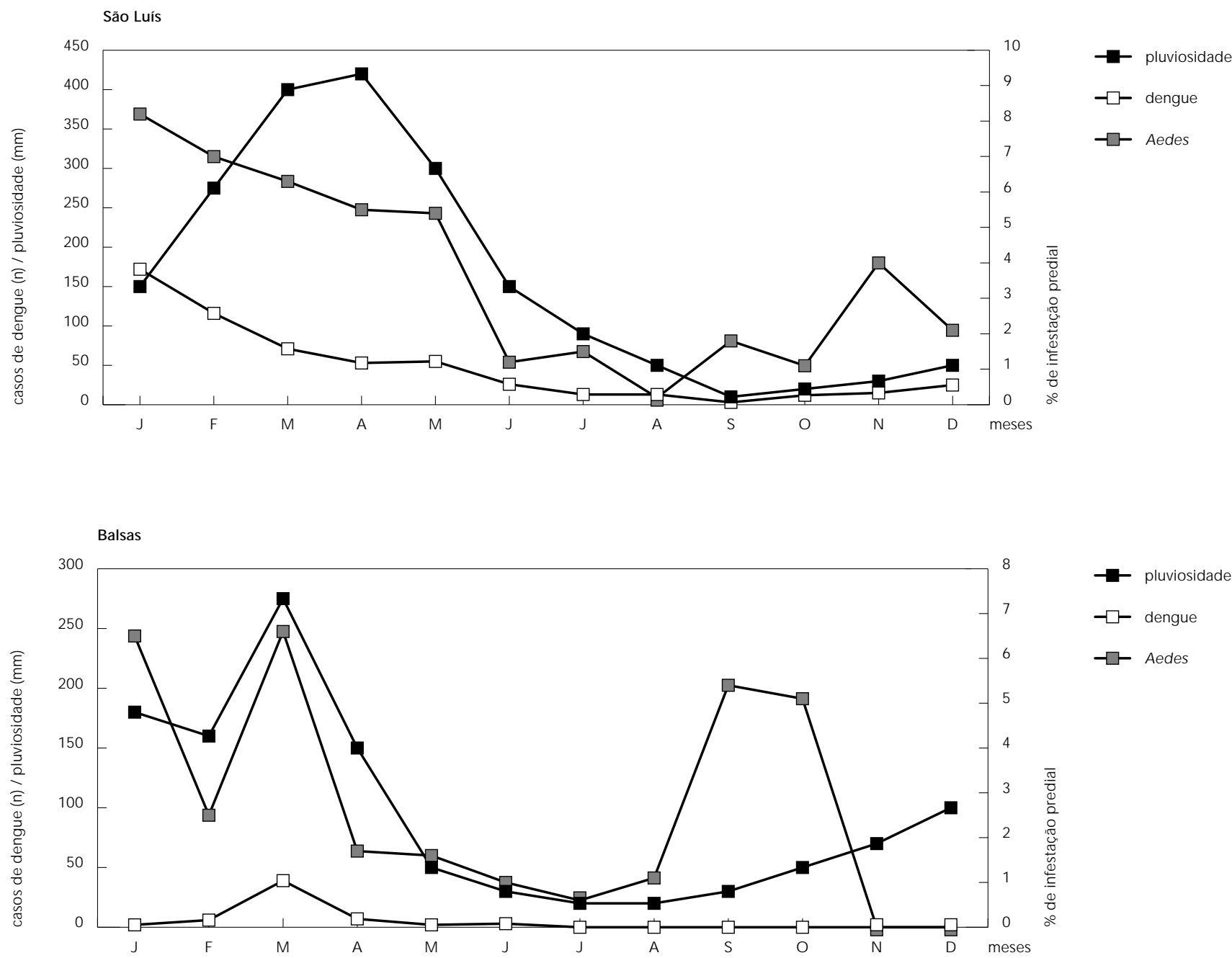

diminuição na incidência do dengue e na atividade reprodutiva das formas adultas. No entanto, ao contrário do que ocorre nas áreas subtropicais, a temperatura constante quase $o$ ano inteiro parece não exercer qualquer influência na abundância mensal desse mosquito, uma vez que varia muito pouco durante o ano, em torno de três graus. O fator limitante, ao que parece, vem sendo a pluviosidade.

Em outras partes do Brasil, em particular nas regiões Sudeste e Centro-Oeste, com a chegada do inverno, caem drasticamente a temperatura e o índice pluviométrico, determinando a diminuição da atividade da forma alada.
Conseqüentemente, o índice de infestação predial diminui e deixa de ocorrer transmissão. Esse período corresponde aos meses de maio a setembro. Durante o verão ocorre o oposto. $O$ aumento da temperatura e das chuvas provoca uma explosão na eclosão dos ovos, com surgimento de milhares de mosquitos adultos.

\section{Agradecimento}

Os autores agradecem à Fundação Nacional de Saúde - MA o fornecimento dos dados aqui apresentados. 


\section{Referências}

CHIARAVALLOTI-NETO, F., 1997. Descrição da colonização de Aedes aegypti na região de São José do Rio Preto, São Paulo. Revista da Sociedade Brasi leira de Medicina Tropical, 30:279-285.

CHIEFFI, P. P., 1985. Algumas questões decorrentes da reintrodução do Aedes aegypti no Brasil. Cadernos de SaúdePública, 1:193-199.

FRANCO, O., 1976. História da Febre Amarela no Brasil. Rio de Janeiro: Ministério da Saúde.

MARQUES, A. C., 1985. Sobre a viabilidade atual de erradicação do Aedes aegypti no controle da febre amarela no Brasil. Revista Brasileira de MalarioIogia eDoenças Tropicais, 37:37-46.

MS (Ministério da Saúde), 1986. Combate ao Aedes aegypti. Instrução para Guardas, Guardas-Chefes e Inspetores. Brasília: Superintendência de Campanhas de Saúde Pública, Ministério da Saúde.
MONDET, B.; ROSA, A. T. \& VASCONCELOS, P. F. C., 1996. Urbanização da febre amarela: Um problema preocupante. Revista da Soci edade Brasileira de Medicina Tropical, 29(Sup.):51.

NEVES, V. L. F. C. \& PINHO, L. A. C., 1996. Aedes ae gypti e Aedes albopictus no Município de São Paulo - SP, 1991 a 1995. Revista da Sociedade Brasileira de Medicina Tropical, 29(Sup.):55.

NEVES, D. P.; MELO, A. L.; GENARO, O. \& LINARDI, P. M., 1995. Culicídeos. In: Parasitologia Humana (D. P. Neves, org.), pp. 383-397, São Paulo: Editora Atheneu.

PESSÔA, S. B. \& MARTINS, A. V. , 1978. Parasitologia Médica. 10a Ed., 1a reimpressão. Rio de Janeiro: Editora Guanabara-Koogan. 